\title{
A Difficult Diagnosis of a Myelodysplastic Syndrome/Myeloproliferative Neoplasm in its Limiting form and Interest of Next Generation Sequencing
}

Benoît Ducourneau ${ }^{1,2 *}$, Nicolas Duployez ${ }^{2}$, Malicka Sanfo $^{1}$, Claire Hemar ${ }^{1}$, Audrey Decambron ${ }^{1}$, José Fernandes ${ }^{3}$, Lina Sabor ${ }^{1}$, Claude Preudhomme $^{2}$ and Hervé Bisiau ${ }^{1}$

${ }^{1}$ Laboratory of Hematology, Hospital Center of Valenciennes, France

${ }^{2}$ Laboratory of Hematology, Biology and Pathology Center, Lille, France

${ }^{3}$ Hematology Department, Hospital center of Valenciennes, France

\section{Introduction}

Myelodysplastic/myeloproliferative neoplasms (MDS/MPN) as chronic myelomonocytic leukemia (CMML), juvenile myelomonocytic leukemia (JMML), atypical chronic myeloid leukemia (CML) BCR$A B 1 L$ negative, MDS/MPN-RS-T and MDS/MPN unclassifiable are defined in the classification WHO 2016. But in this classification, MDS/ MPN unclassifiable is the less defined his category and is a diagnosis of exclusion.

These forms of MDS/MPN unclassifiable (MDS/MPN-U) have often a normal karyotype or show abnormalities in common with MDS. In absence of those cytogenetics abnormalities, this pathology is characterized by the presence of dysplasia over one or more lineage, cytopenia, no excess of blast in the bone marrow $(<5 \%)$ and blood $(<1 \%)$ and usually, there is a granulocytic or thrombocytic proliferation.

So, it is difficult to classify some patients on the simple clinical, cytological and cytogenetical presentation. Generally, the molecular biology is used to research a MPN molecular abnormally. Thus, without MPN molecular abnormally, it is important to realize a mutational profile of a suspected MDS/MPN-U.

\section{Case and Methods}

We report the case of a patient diagnosed in 2017 in $\mathrm{CH}$ Valenciennes. The diagnosis was established on the data of cytology (hemograms, myelogram), cytogenetics/FISH (medullary karyotype) and molecular biology.

A 65-year-old man was admitted in emergencies for a change of general state, asthenia, paleness and a loss of weight. At the entrance, the full blood count revealed a non-regenerative anemia ( $\mathrm{Hb}: 6.9 \mathrm{~g} /$ $\mathrm{dL}$, reticulocytes: $95 \times 10^{9} / \mathrm{L}$ ), a hyperleukocytosis (WBC: $118 \times 10^{9} / \mathrm{L}$ ) and a thrombopenia (platelets: $63 \times 10^{9} / \mathrm{L}$ ). The peripheral blood smear demonstrated an important increased number of white blood cells. The formula shows $76 \%$ neutrophils $\left(86 \times 10^{9} / \mathrm{L}\right), 20 \%$ immature granulocytes and $1 \%$ of blast with granulocytes hypogranulation. The following formulas do not still show the presence of blast.

A bone marrow biopsy showed a hypercellular. Megakaryocytes were normal. We noticed a hyperplasia of granulocyte lineage with a respected maturation and a moderate hypogranulation. Erythroblastic lineage was discreetly decreased. There was no excess of blasts (4\%). The cytological aspect suggested a myeloproliferative neoplasm (MPN). Bone marrow conventional cytogenetic analysis revealed a male karyotype without abnormaly. The fluorescence in situ hybridization (FISH) was also negative.

Molecular biology was then essential to the malignant blood disease diagnosis. The research for $B C R-A B L 1$ was negative in PCRRT. JAK2 mutation by digital PCR, CALR mutation by analysis of fragment and Sanger, MPL mutation by HRM (High Resolution Melt) and Sanger were all negative. A research of atypical fusion transcript in
MLPA-RT (Reverse Transcriptase Multiplex Ligation-dependant Probe Amplification) was also negative.

Finally, the final possibility was to establish a molecular profile of myeloid neoplasm, a high throughput sequencing targeting 36 genes was realized. Next generation sequencing showed the presence of six mutations: ASXL1 (Variant allele frequency [VAF] 50\%), EZH2 (VAF 50\%), CBL (VAF 3\%), NRAS (VAF 46\%), RUNX1 (45\%), SMC3 (VAF $50 \%)$.

\section{Discussion}

Diagnosis is not possible with cytological, cytogenetically and basic molecular biology. Next generation sequencing allows to detect several mutations to give an indication to the malignant blood disease. In fact, each mutation is present in different pathology.

ASXL1 mutations, gene involved in the reshaping of the chromatine [1], are frequently detected in myeloid malignant blood disease (CMML, MDS, AML (acute myeloid leukemia)) [2] and present a poor prognosis [3].

CBL mutations, gene coding for an ubiquitine ligase allowing the ubiquitination of many substrats and then those substrate are deteriorate by the proteasome [4], are detected in MDS/MPN, CMML, JMML [5]. EZH2 mutations, a repressor gene of transcription [6], are detected in MDS and MDS/MPN [7]. NRAS mutations, affect intracellular way RAS and play an important role in the regulation of proliferation, survival, differentiation and cellular migration [8], are detected in MDS with a higher risk of transformation into AML [9].

RUNX1 mutations, gene coding for sub-unit of the heterodimeric complex core binding factor (CBF) and conferring a high stability on the DNA, essential to the definitive hematopoiesis [10] , are detected in MDS, AML and CMML [11,12]. SMC3 mutations, composant of cohesin complex which allows the sister chromatid stability during the mitotic division [13], are detected in MDS, CMML, MPN and AML [14]. Mutational profile of malignant blood disease gives an indication to the diagnosis of limiting forms of MDS/MPN.

*Corresponding author: Benoît Ducourneau, Laboratory of Hematology, Hospital Center of Valenciennes, France, Avenue Desandrouins, 59300, Valenciennes Cedex, France, Tel: +33(0)3.27.14.33.33; E-mail: ducourneau-b@ch-valenciennes.fr

Received February 15, 2018; Accepted February 20, 2018; Published February 26, 2018

Citation: Ducourneau B, Duployez N, Sanfo M, Hemar C, Decambron A, et al (2018) A Difficult Diagnosis of a Myelodysplastic Syndrome/Myeloproliferative Neoplasm in its Limiting form and Interest of Next Generation Sequencing. J Blood Lymph 8: 206. doi:10.4172/2165-7831.1000206

Copyright: $\odot 2018$ Ducourneau B, et al. This is an open-access article distributed under the terms of the Creative Commons Attribution License, which permits unrestricted use, distribution, and reproduction in any medium, provided the original author and source are credited. 
Citation: Ducourneau B, Duployez N, Sanfo M, Hemar C, Decambron A, et al. (2018) A Difficult Diagnosis of a Myelodysplastic Syndrome/ Myeloproliferative Neoplasm in its Limiting form and Interest of Next Generation Sequencing. J Blood Lymph 8: 206. doi:10.4172/21657831.1000206

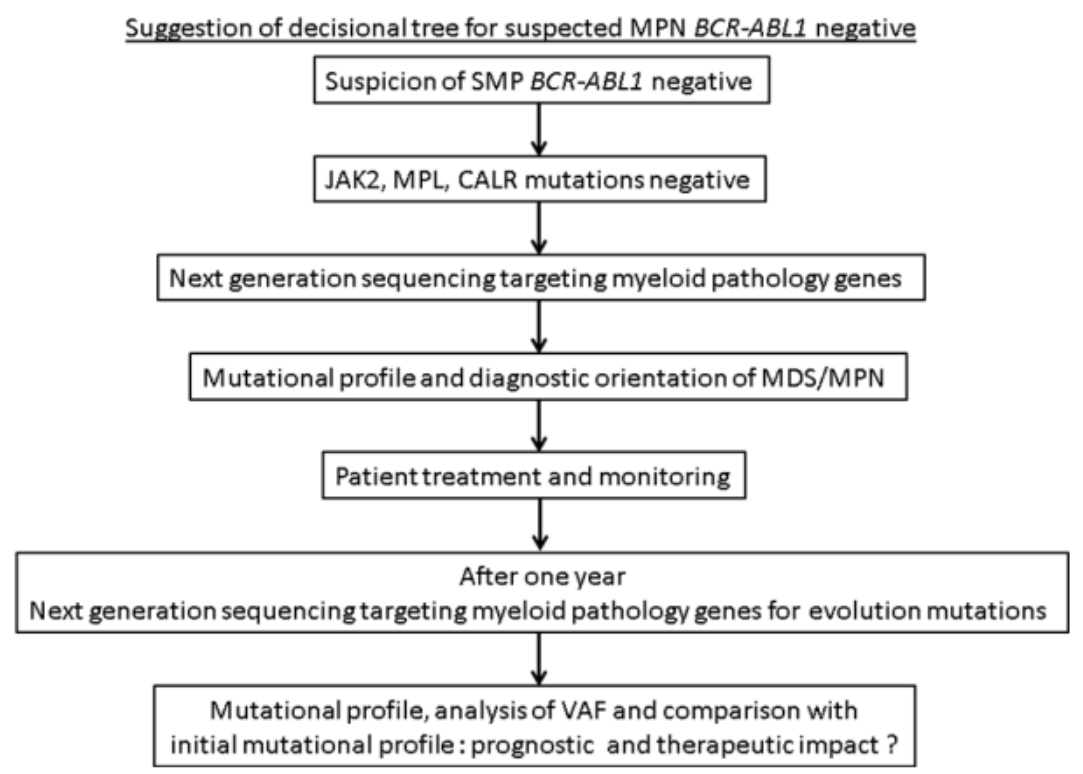

Figure 1: Suggestion of decisional tree for suspected MPN BCR-ABL1 negative.

\section{Conclusion}

This case confirms the complexity the MDS/MPN-U diagnosis. This diagnosis requires cytological and cytogenetically analysis, and particularly a myeloid molecular analysis.

It's mandatory for a differential diagnosis to search the genes classically found in MPN BCR-ABL1 negative (JAK2, MPL, CALR). The high throughput sequencing of 36 genes allows us to obtain a mutational profile of the myeloid blood disease and give an indication for the diagnosis (Figure 1).

In our case report, the next generation sequencing allowed to classify the patient in a limiting form MDS/MPN. This patient presents a higher risk of transformation into AML. He is now treated by cytoreductive agent. It is necessary to follow the molecular and cytological evolution of this patient. The presence of new molecular alteration could impact the prognosis and change the treatment.

\section{References}

1. Abdel-Wahab O, Adli M, LaFave LM, Gao J, Hricik T, et al. (2012) ASXL1 mutations promote myeloid transformation through loss of PRC2-mediated gene repression. Cancer Cell 22: 180-193.

2. 2. Gelsi-Boyer V, Trouplin V, Adélaïde J, Bonansea J, Cervera N, et al. (2009) Mutations of polycomb-associated gene ASXL1 in myelodysplastic syndromes and chronic myelomonocytic leukaemia. $\mathrm{Br} \mathrm{J}$ Haematol 145: 788-800.

3. Schnittger S, Eder C, Jeromin S, Alpermann T, Fasan A, et al. (2013) ASXL1 exon 12 mutations are frequent in AML with intermediate risk karyotype and are independently associated with an adverse outcome. Leukemia 27: 82-91.

4. Thien CB, Langdon WY (2005) Negative regulation of PTK signalling by Cbl proteins. Growth Factors 23: 161-167.
5. Loh ML, Sakai DS, Flotho C, Kang M, Fliegauf M, et al. (2009) Mutations in CBL occur frequently in juvenile myelomonocytic leukemia. Blood 114: 1859-1863.

6. Ernst T, Chase AJ, Score J, Hidalgo-Curtis CE, Bryant C, et al. (2010) Inactivating mutations of the histone methyltransferase gene EZH2 in myeloid disorders. Nat Genet 42: 722-726.

7. Herviou L, Cavalli G, Cartron G, Klein B, Moreaux J, et al. (2016) EZH2 in normal hematopoiesis and hematological malignancies. Oncotarget 7: 22842296.

8. Renneville A, Roumier C, Biggio V, Nibourel O, Boissel N, et al. (2008) Cooperating gene mutations in acute myeloid leukemia: a review of the literature. Leukemia 22: 915-931.

9. Bejar R (2014) Clinical and genetic predictors of prognosis in myelodysplastic syndromes. Haematologica 99: 956-964.

10. Swiers G, de Bruijn M, Speck NA (2010) Hematopoietic stem cell emergence in the conceptus and the role of Runx1. Int J Dev Biol 54: 1151-63.

11. Christiansen DH, Andersen MK, Pedersen-Bjergaard J (2004) Mutations of AML1 are common in therapy-related myelodysplasia following therapy with alkylating agents and are significantly associated with deletion or loss of chromosome arm $7 q$ and with subsequent leukemic transformation. Blood 104 1474-1481.

12. Harada H, Harada $Y$, Niimi H, Kyo T, Kimura A, et al. (2004) High incidence of somatic mutations in the AML1/RUNX1 gene in myelodysplastic syndrome and low blast percentage myeloid leukemia with myelodysplasia. Blood 103: 2316-2324.

13. Solomon DA, Kim T, Diaz-Martinez LA, Fair J, Elkahloun AG, et al. (2011) Mutational inactivation of STAG2 causes aneuploidy in human cancer. Science 333: 1039-1043

14. Thota S, Viny AD, Makishima H, Spitzer B, Radivoyevitch T, et al. (2014) Genetic alterations of the cohesin complex genes in myeloid malignancies. Blood 124: 1790-1798. 